\title{
Large Scale Production of Densified Hydrogen to the Triple Point and Below
}

\author{
A M Swanger ${ }^{1}$, W U Notardonato 1 , J E Fesmire ${ }^{1}$, K M Jumper ${ }^{1}$, W L Johnson ${ }^{2}$, \\ and T M Tomsik ${ }^{2}$ \\ ${ }^{1}$ NASA Kennedy Space Center, Cryogenics Test Laboratory, FL 32899 USA \\ ${ }^{2}$ NASA Glenn Research Center, Cleveland, OH 44135 USA \\ Email: adam.m.swanger@nasa.gov
}

\begin{abstract}
Recent demonstration of advanced liquid hydrogen storage techniques using Integrated Refrigeration and Storage technology at NASA Kennedy Space Center led to the production of large quantities of densified liquid and slush hydrogen in a 125,000 L tank. Production of densified hydrogen was performed at three different liquid levels and $\mathrm{LH}_{2}$ temperatures were measured by twenty silicon diode temperature sensors. Overall densification performance of the system is explored, and solid mass fractions are calculated. Experimental data reveal hydrogen temperatures dropped well below the triple point during testing, and were continuing to trend downward prior to system shutdown. Sub-triple point temperatures were seen to evolve in a time dependent manner along the length of the horizontal, cylindrical vessel. The phenomenon, observed at two fill levels, is detailed herein. The implications of using IRAS for energy storage, propellant densification, and future cryofuel systems are discussed.
\end{abstract}

\section{Introduction}

Fluid-based fuels and/or oxidizers are routinely stored on-board vehicles of various types in order to provide chemical potential for an engine. In the vast majority of these applications the fluids are stored in a liquid state due to the significantly larger stored energy capacity compared to the gaseous phase, and can be kept at much lower pressures, avoiding the need for heavy pressure vessels. In either case, the key point is that the fluid acts as an energy carrier, therefore, the denser the fluid the greater the energy stored in a given volume. This is especially important in applications where the transportation of energy in fluid form is the express purpose, such as in ocean-going and roadable tankers.

The term "densification" refers to the process of thermodynamically manipulating a fluid with the intent of increasing its density above that of a typical reference value, thereby increasing its energy storage potential. Reference values usually correspond to atmospheric conditions (temperature, pressure, or both), and in the case of cryogenic propellants such as liquid hydrogen $\left(\mathrm{LH}_{2}\right)$, liquid methane or natural gas (LNG), and liquid oxygen (LOX), the reference density is that realized at the normal boiling point (NBP); i.e. when the fluid is completely saturated at atmospheric pressure.

Historically, the maximum attainable cryofuel density has corresponded to the NBP storage condition. This constraint has been an important driver for the design of any application that utilizes cryogenic propellants, most notably rocket-powered launch vehicles, by effectively dictating the required flight tank volumes. Therefore, increasing the density of the propellants can have a substantial effect on the overall vehicle design and/or performance. This is especially true for rockets utilizing $\mathrm{LH}_{2}$. 
Due to its low density, vehicle $\mathrm{LH}_{2}$ tanks need to be very large (roughly 2.5 times larger than the LOX tank); which, for large vehicles such as the Space Shuttle that required about 103,000 kg of hydrogen on-board at lift-off, means that the $\mathrm{LH}_{2}$ tank is the dominating feature of the vehicle volume envelope.

Numerous studies have been conducted that explored the benefits of densified propellants, and it has been reported that the positive impact on payload mass fraction can be quite significant, ranging from $4.9 \%$ to $17.5 \%$ to low-Earth orbit depending on launch platform and densification temperatures, and up to $26 \%$ if slush hydrogen $\left(\mathrm{SH}_{2}\right)$ is employed [1-4]. These benefits have prompted the aerospace industry to explore the use of densified hydrogen $\left(\mathrm{DH}_{2}\right)$ over the years. The National Bureau of Standards quantified the thermodynamic properties of $\mathrm{DH}_{2}$ and $\mathrm{SH}_{2}$ in the 1960's, and Martin Marietta studied densified propellants for a Single Stage to Orbit launch system in the late 1970s [5]. From 1988 to 1994, NASA Glenn Research Center (GRC) worked on $\mathrm{SH}_{2}$ production and transfer for the National Aerospace Plane (NASP), producing 3,028 liter batches using evaporative cooling in a freeze/thaw cycle [6]. GRC continued development for another 8 years with several advances working with the X-33 program, including construction of two densifier units $(0.9 \mathrm{~kg} / \mathrm{sec}$ and $3.6 \mathrm{~kg} / \mathrm{sec})$, and conducted several transfer and loading demonstrations [7-9]. At this time, the Space Shuttle program considered switching to densified propellants as an upgrade to launch more mass to orbit, but operational concerns and the need for a costly engine recertification effort resulted in the decision to pursue the super-lightweight external tank modification instead [10]. NASA continued development of densifier systems with the 2nd Generation Reusable Launch Vehicle program, funding three separate contracts to build prototype units and investigate refrigeration technologies [11]. Around this same time, NASA KSC and the Florida Solar Energy Center (FSEC) produced densified hydrogen on a small scale (180 liter) using an integrated Gifford-McMahon refrigerator and dewar [12]. This Integrated Refrigeration and Storage (IRAS) approach laid the groundwork for the large scale $\mathrm{DH}_{2}$ effort reported here.

Most recently, NASA's Advanced Engineering Systems program funded development of a new type of large scale hydrogen densifier at KSC deemed the Ground Operations Demonstration Unit for Liquid Hydrogen (GODU-LH2) that IRAS technology [13]. This system was tested throughout 2015, and represented a 700 fold increase in volumetric scale compared to the previously mentioned FSEC effort. $\mathrm{LH}_{2}$ was successfully densified within a 125,000 liter storage tank at three different level levels, and even produced large batches of $\mathrm{SH}_{2}$. Such a significant increase in scale was crucial to demonstrating the capability of IRAS to produce densified hydrogen in quantities relevant to actual launch facilities.
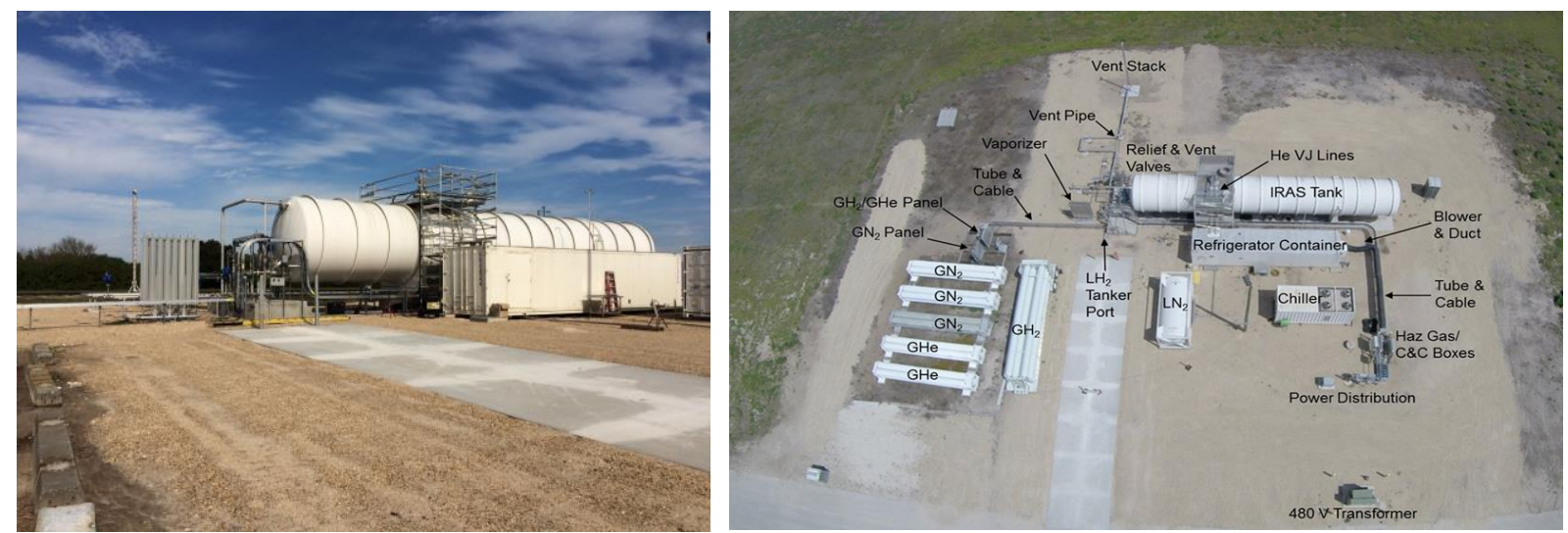

Figure 1. GODU-LH2 Test Site: Ground Level View (Left); Overhead View (Right)

\section{IRAS Densification Methodology}

Densification of $\mathrm{LH}_{2}$ can be achieved in one of three ways: (1) lowering the vapor pressure by pulling a vacuum on the ullage-space, thereby causing the liquid to boil and cool down to reach the new saturation condition; (2) injecting gaseous helium into the $\mathrm{LH}_{2}$ and allowing it to bubble up, cooling the liquid via evaporation at the bubble surface; and (3) direct removal heat from the liquid using a heat exchanger and separate refrigerant fluid. A prime benefit of the first method is that the storage tank can be relatively 
simple; however, the system requires complex cold-rotating equipment (vacuum pumps), and hydrogen must be sacrificed in order to create a batch of $\mathrm{DH}_{2}$. Method two expends huge quantities of costly helium in order to produce batches of $\mathrm{DH}_{2}$ on a relevant scale. Therefore, it is not considered to be practical for large systems such as those at launch sites. The third method is alluring because the system can be completely closed, therefore no hydrogen is lost during densification, and the cold-rotating equipment (refrigerator) can be procured "off-the-shelf" by numerous vendors. However, this method does require a more complicated storage tank and integration of components.

IRAS employs the third method by using an internal tank heat exchanger that is directly coupled to the liquid (i.e. submerged). This approach expedites heat transfer between the hydrogen and refrigerant by minimizing thermal resistances; and, if a DC cycle refrigerator is utilized, the cold power can be efficiently distributed throughout the entire tank volume.

\section{GODU-LH2 System Overview}

A simplified functional diagram of the GODU-LH2 system is given in Figure 2, and depicts how the primary subsystems are integrated. Central to the design is the aforementioned 125,000 liter IRAS tank. This vessel was originally constructed in 1991 and used by the Titian-Centaur program as NBP $\mathrm{LH}_{2}$ storage at launch complex 40 at the Cape Canaveral Air Force Station, but was repurposed for GODULH2 in 2011. It is a horizontal-cylindrical configuration, vacuum-jacketed with 80 layers of multi-layer insulation, and has a steady-state heat leak of roughly $300 \mathrm{~W}$ (verified by $\mathrm{LH}_{2}$ boil-off testing). Five primary modifications were required to transform this standard NBP tank into a next generation IRAS smart-tank: (1) construction of the internal IRAS heat exchanger, (2) internal stiffening rings to accommodate the sub-atmospheric pressure associated with densification testing, (3) an updated manway feed-through plug to incorporate instrumentation and refrigerant penetrations, (4) recertification of the tank per the American Society of Mechanical Engineers (ASME) Boiler and Pressure Vessel Code (BPVC) to the new operating conditions, and (5) temperature rakes to map the vertical, axial and radial tank temperature profile (20 silicon diodes in total). Details regarding the design and construction of the IRAS tank have been extensively covered in previous publications [14 \&15].

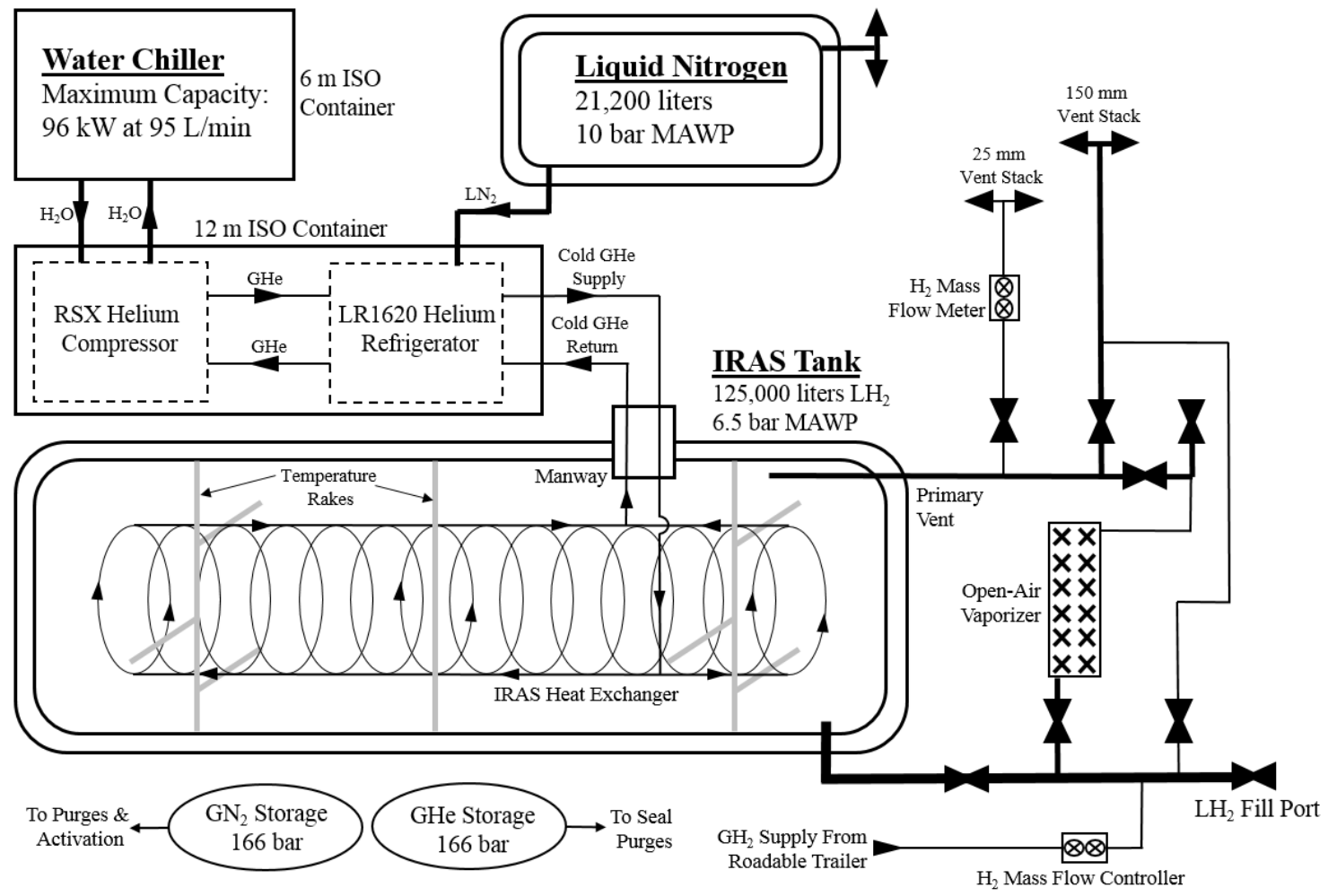

Figure 2. GODU-LH2 Simplified Functional Diagram 
The IRAS heat exchanger is supplied with approximately $22 \mathrm{~g} / \mathrm{s}$ of cold gaseous helium from a Linde LR1620 refrigerator - a Brayton cycle unit with piston expansion and provisions for liquid nitrogen $\left(\mathrm{LN}_{2}\right)$ pre-cooling. The refrigerator has rated capacities of $880 \mathrm{~W}$ and $390 \mathrm{~W}$ at $20 \mathrm{~K}$, with without and $\mathrm{LN}_{2}$ precooling respectively, and employs independent command and control and instrumentation. The cycle is driven by an RSX helium compressor that includes systems for oil separation and gas management. The entire refrigeration system is housed in a standard $12 \mathrm{~m}$ ISO shipping container to allow for transportation to other test facilities in the future.

In addition to the IRAS tank and refrigeration system, the GODU-LH2 site includes the usual support systems such as pneumatics, command and control, transfer systems, communications and instrumentation. The pneumatic system includes fixed gaseous nitrogen and gaseous helium storage bottles and provisions for tube trailers of gaseous hydrogen. The transfer system includes the VJ transfer lines, vent lines, vaporizer, and associated manual and remote control valves. The command and control/data acquisition system had to integrate separate systems for the refrigerator.

Densification tests were conducted at three liquid level (46\%, 67\% and 100\%). During each densification test, the tank liquid and vent valves are closed and the tank is locked up. The refrigerator was run at full capacity with $\mathrm{LN}_{2}$ precooling active. During densification operations, the IRAS tank pressure and liquid temperature decrease as long as the refrigerator lift is greater than the tank heat leak.

There is no helium gas pressure applied to the ullage and the tank pressure does go below atmospheric pressure. When the tank reaches the NBP, a low pressure helium gas purge is applied to the stem seals, backside of all isolation valves, and around the perimeter of all the flanges to prevent the intrusion of atmospheric air in the event of a leak. Eventually the system reaches an equilibrium temperature where the cryocooler refrigeration power will equal the heat load on the tank and refrigeration system. The pretest estimated minimum temperature for the system was around $15 \mathrm{~K}$. Data was collected on heat exchanger and refrigerator performance and on the response of the liquid and vapor in the tank.

\section{Densification Test Results}

Densification testing at all three fill levels successfully met the pre-test prediction of $15 \mathrm{~K}$ bulk liquid temperatures. For the $46 \%$ and $67 \%$ tests the triple point was reached $(13.8 \mathrm{~K} \& 0.07$ bara) and slush hydrogen was produced. The $100 \%$ test was progressing towards the triple point but was terminated due to project funding at the end of fiscal year 2016. Details of each individual test are discussed below. Table 1 shows IRAS tank information at the six vertical diode locations on the center temperature rake.

Table 1. IRAS Tank Information at Center Rake Diode Locations

\begin{tabular}{cccc}
\hline Diode \# & Vertical Elevation (m) & Fill Level & Approx. $\mathrm{LH}_{2}$ Volume (L) \\
\hline TT3 & 0.57 & $15 \%$ & 19,100 \\
TT4 & 0.92 & $30 \%$ & 37,900 \\
TT9 & 1.24 & $46 \%$ & 57,000 \\
TT10 & 1.54 & $61 \%$ & 76,100 \\
TT15 & 1.85 & $76 \%$ & 95,200 \\
TT16 & 2.12 & $88 \%$ & 110,200 \\
\hline
\end{tabular}

\section{1. $46 \%$ liquid level}

Densification testing at the 46\% fill level was conducted in March and April of 2016. Common for each densification test series, the IRAS tank was locked up and the refrigerator was operated at full capacity, with $\mathrm{LN}_{2}$ precooling. Once the tank pressure became subatmospheric a test officially began; at the $46 \%$ fill level this took place the morning of March $24^{\text {th }}$, and is designated as T- 0 in figure 2.

The test period shown in Figure 2 covers the entire time that the tank pressure was subatmospheric. The refrigerator was operating until time $T+330$ hours, when the helium compressor failed and needed to be replaced. The response of the tank pressure and rake temperatures show similar behaviors: a steady 
decrease before gradually slowing down and flattening out at or near the triple point. Spikes in the curves at $\mathrm{T}+120$ hours and $\mathrm{T}+170$ hours were due to temporary shutdowns of the refrigerator for valve adjustments, and a third spike at $\mathrm{T}+260$ hours was from a lapse of $\mathrm{LN}_{2}$ pre-cooling.

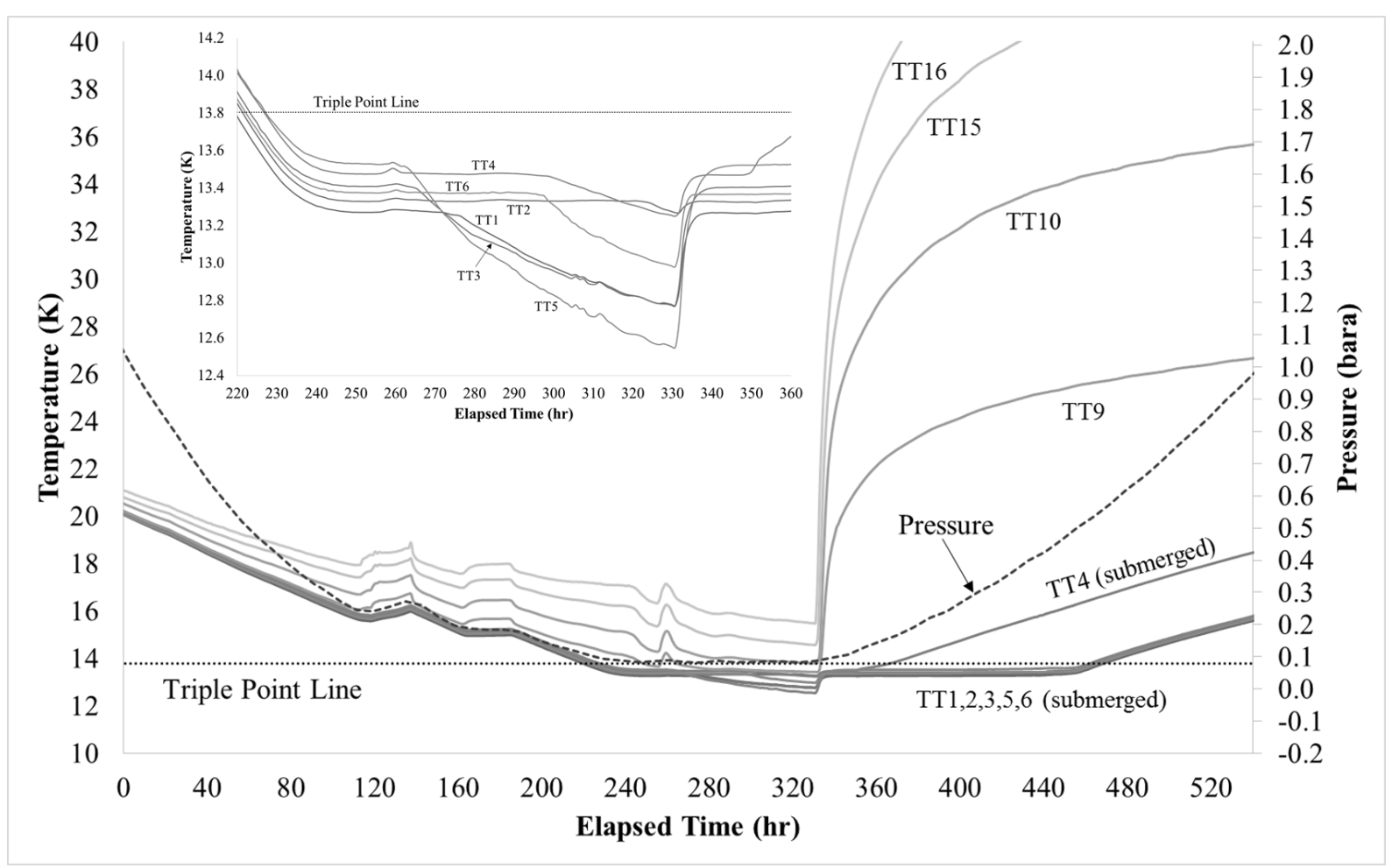

Figure 2. IRAS Tank Pressure and Temperature Profile at the $46 \%$ Fill Level

(Embedded plot at top left shows a more detailed view of $\mathrm{LH}_{2}$ temperatures at the triple point)

Three notable features are revealed in figure 2 - and will be seen again in the $67 \%$ test data. First is the proximity of the pressure and bottom-most temperatures to the triple point (TP) of pure parahydrogen (i.e. the "Triple Point Line"). TT1 through TT6 were submerged in liquid during this test, and TT9 was very close to the liquid-vapor interface. These temperatures flattened out close to, but below the triple point $(0.42 \mathrm{~K}$ lower on average), while the pressure flattened out almost directly on the line, coming to within 0.002 bara. It is believed that the low temperatures compared to the TP was due to instrumentation bias, and/or binary mixture effects caused by dissolved helium refrigerant that may have leaked into the $\mathrm{LH}_{2}$ through the IRAS heat exchanger fittings. This trend was also seen with respect to the NBP during all three steady-state boil-off tests, where the submerged diodes averaged $0.18 \mathrm{~K}$ lower.

Secondly, upon shutdown TT1, 2, 3, $5 \& 6$ rose back to the triple point and remained there for approximately 100 hours before rising at the $\mathrm{T}+460$ hour mark. This was taken as evidence of solid-toliquid phase change, and was subsequently used to estimate the quantity of solid hydrogen formed during the test. Via analysis and steady state boil-off data it was estimated that at the $46 \%$ fill level the heat load on the liquid region was $178 \mathrm{~W}$. The heat of fusion of para-hydrogen was taken to be $62.8 \mathrm{~kJ} / \mathrm{kg}$ [16], and assuming the entire $178 \mathrm{~W}$ went into thawing the hydrogen ice over the 100 hour duration, calculations show that roughly $1,020 \mathrm{~kg}$ of solid was formed during the test. This translates to a maximum solid-to-liquid mass fraction of roughly $25 \%$, or about 11,780 liters of hydrogen ice.

Last is the abrupt drop below the triple point by TT5 at roughly T+260 hours, after a lengthy stay at that condition; followed closely by TT3, and then in succession by TT1, TT6, TT5, and TT2 just before refrigerator shutdown. Each of these sensors are at the same elevation, save TT4, which is $0.35 \mathrm{~m}$ higher, and are positioned below the bottom heat exchanger manifold (i.e. the inlet manifold). TT2 and TT6 are located near the tank wall while all others are positioned along the tank centerline. TT5 is closest to 
the cold helium inlet to the heat exchanger, followed by TT3, and then TT1. The data seem to suggest that this supercooling phenomenon evolves in time, originating at the coldest part of the heat exchanger and spreading axially down the manifold, and radially outwards. This behavior is somewhat counterintuitive, and not fully understood at this time. Some effort needs to be spent to explain how, what appears to be supercooling of the bulk liquid (or slush), can be coincident with a phase change.

\section{2. $67 \%$ liquid level}

Figure 3 shows the results of densification testing at the $67 \%$ fill level. The test began on the morning of June $30^{\text {th }} 2016$ (T-0 in figure 3), and ended on July $25^{\text {th }} 2016$.

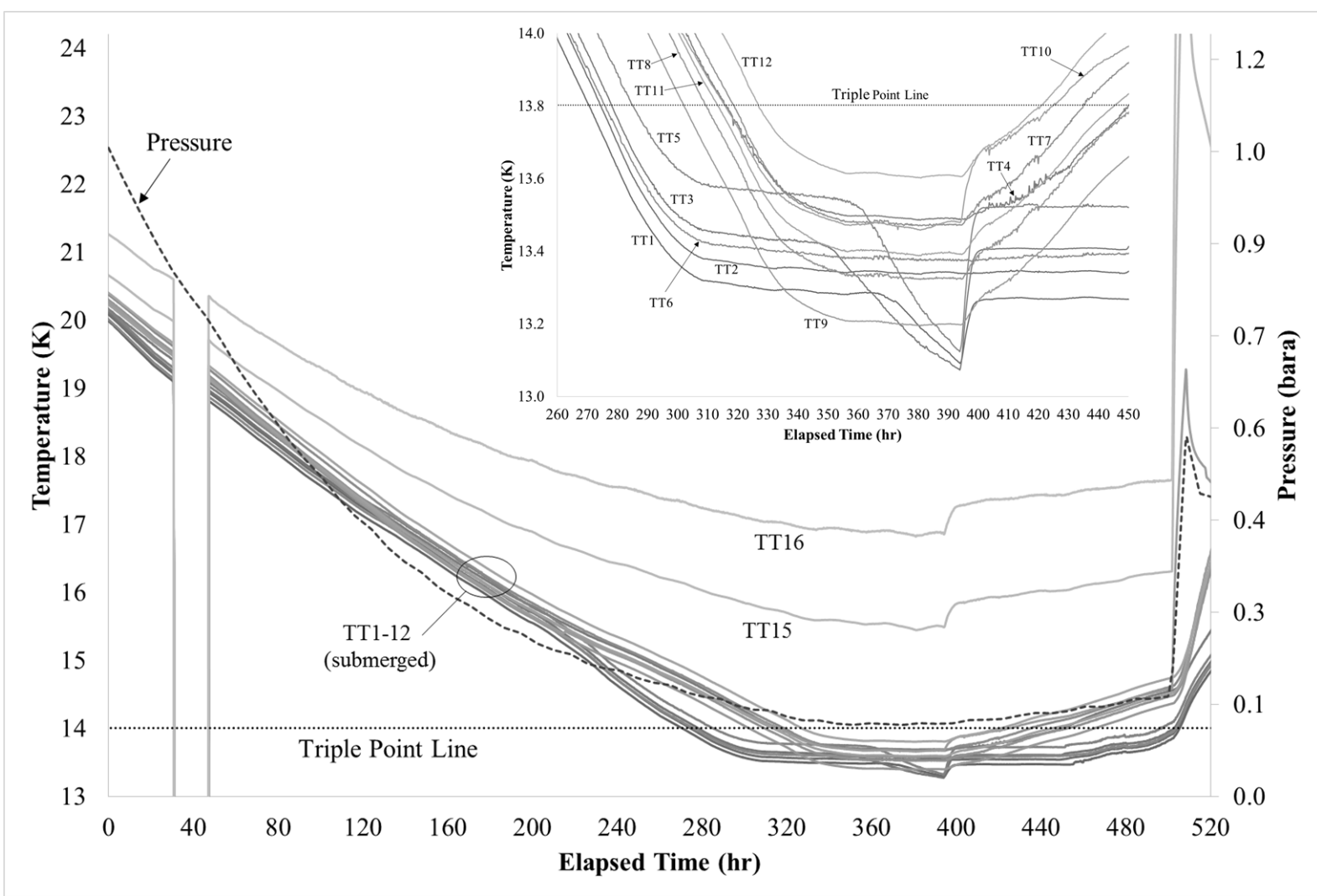

Figure 3. IRAS Tank Pressure and Temperature Profile at the 67\% Fill Level

(Embedded plot at top right shows a more detailed view of $\mathrm{LH}_{2}$ temperatures at the triple point)

Figure 3 reveals trends similar to those seen in the $46 \%$ fill test. As expected, the time scales were longer due to the additional $1,900 \mathrm{~kg}$ of hydrogen mass, requiring around 300 hours to reach the TP versus 240 hours at the $46 \%$ fill level. Once again diode readings fell below the triple point line, and temperatures eventually dropped below the true triple point after having previously been stablealthough, prior to dropping, TT1, $3 \& 5$ seemed to show a slight downward trend after reaching the triple point, whereas in the $46 \%$ test they were essentially flat.

An interesting difference between figures 2 and 3 is the separation in submerged temperatures seen at the 230 hour mark. Prior to this time all of the submerged temperatures were trending together, at which point a group of five sensors underwent a period of accelerated cooling, resulting in them reaching the triple point roughly 40 hours sooner than the other group. Closer examination revealed that the five sensors to reach the triple point first all resided at the same elevation (same as TT3, see table 1), and were all positioned below the bottom heat exchanger manifold.

Unlike the end of $46 \%$ test, the refrigerator was not turned off at the conclusion of the $67 \%$ effort. Instead, beginning at approximately $\mathrm{T}+395$ hours, $\mathrm{LN}_{2}$ precooling was turned off and the system was 
run for $100+$ hours to try to determine if the triple point conditions could be maintained without the use of $\mathrm{LN}_{2}$. Unfortunately, the heat leak at those temperatures overcame the refrigerator capacity and the tank gradually started to warm up around $\mathrm{T}+460$. At $\mathrm{T}+500$ hours a gaseous hydrogen supply was introduced into the tank, allowing it to increase back to atmospheric pressure more quickly.

Estimating the quantity of hydrogen ice created at the $67 \%$ fill level was more difficult than in the $46 \%$ test because the refrigerator was still removing and unknown amount of heat from the liquid region after $\mathrm{LN}_{2}$ precooling was turned off. Between $\mathrm{T}+401$ hours and $\mathrm{T}+452$ hours the heat load on the liquid region was estimated to be $196 \mathrm{~W}$. If this was the sole heat load, as it was in the $46 \%$ test, it would result in roughly $573 \mathrm{~kg}$ of solid having been generated, or a solid-to-liquid mass fraction of $6.3 \%$. In actuality, these values were much lower due to the additional heat rejection provided by the refrigerator.

\section{3. $100 \%$ liquid level}

Testing at the 100\% fill level occurred between September and October 2016, and successfully densified approximately 121,000 liters of $\mathrm{LH}_{2}$ to an average temperature of $15.5 \mathrm{~K}$ in 300 hours. As previously mentioned, due to the end of the fiscal year, testing was terminated prior to reaching the triple point. The system was allowed to warm back to the NBP and put into a safe venting mode until all the hydrogen boiled away, and then the IRAS tank will be purged with gaseous nitrogen.

\section{Summary of Results}

A comparison of the densification timelines for the different liquid levels is shown in Figure 4. As expected, the amount of time required to change the storage state is directly proportional to the amount of mass in the tank. At the $46 \%$ liquid level the system required just 107 hours to densify to a saturated pressure of 0.24 bara, while the $67 \%$ fill test took 181 hours to densify to the same condition, and the $100 \%$ full test took 298 hours. At the moment in testing the tank reaches the NBP (T-0 in figure 4), the $46 \%$ full tank is depressurizing at a rate of $0.010 \mathrm{bar} / \mathrm{hr}$, compared to $0.007 \mathrm{bar} / \mathrm{hr}$ for the $67 \%$ full tank and just $0.003 \mathrm{bar} / \mathrm{hr}$ for the completely full tank.

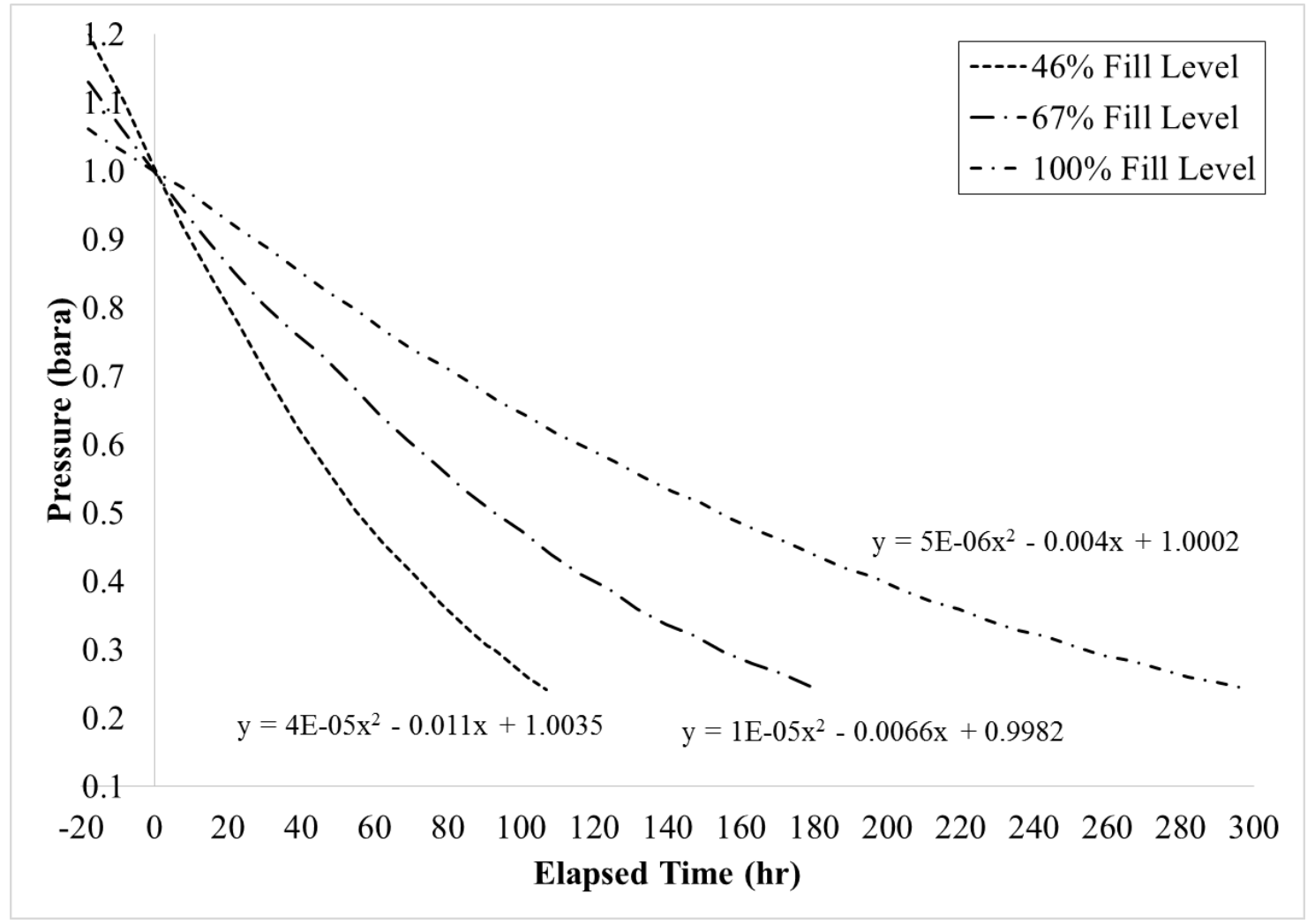

Figure 4. Comparison of Densification Timelines 


\section{Conclusion}

Using a method called Integrated Refrigeration and Storage, NASA cryogenic engineers have demonstrated the capability to produce large batches of densified hydrogen. A Linde LR1620 Brayton cycle refrigerator capable of producing $880 \mathrm{~W}$ of cooling at $20 \mathrm{~K}$ was integrated into a 125,000 liter $\mathrm{LH}_{2}$ dewar using an internal heat exchanger distributed throughout the tank volume. The vessel was locked up and the refrigerator was run at full power to densify the $\mathrm{LH}_{2}$ at three different liquid levels $(46 \%$, $67 \%$ and $100 \%$ ). All tests were successful, with the lower two liquid levels achieving a hydrogen slush mixture with a maximum solid-to-liquid mass fraction around $25 \%$. The $100 \%$ fill level test was displaying similar behavior, trending towards the triple point, but was terminated early due to schedule.

\section{References}

[1] Friedlander M, Zubrin R, and Hardy T 1991 Benefits of Slush Hydrogen for Space Missions, NASA TM 104503

[2] Fazah M 1994 STS Propellant Densification Feasibility Study Data Book, NASA TM 108467,

[3] LeMoyne R 2008 Fundamental Analysis of Cryogenic Propellant Densification, 15th AIAA International Space Planes and Hypersonic Systems and Technologies Conference, Dayton OH, AIAA 2008-2500

[4] Haberbusch M S 2002 Study Task for Determining the Effects of Boost-Phase Environments on Densified Propellants Thermal Conditions for Expendable Launch Vehicles, NASA/CR2002-210808

[5] Ewart R and Dergance R 1977 Cryogenic Propellant Densification Study, Final Report NASA Lewis Research Center Contract Number NAS3-21014

[6] DeWitt R and Hardy T 1989 Slush Hydrogen Technology Development for Application to the National Aerospace Plane, NASA TM 102315

[7] Tomsik T M 1997 Performance Tests of a Liquid Hydrogen Propellant Densification Ground Support System for the X33/RLV, NASA TM-107469, AIAA-97-2976

[8] McIntosh G E, Stochl R J and Tomsik T J 1998 Liquid Hydrogen Densification Heat Exchanger, Advances in Cryogenic Engineering, Vol. 43

[9] Tomsik T M, and Meyer M L 2010 Liquid Oxygen Propellant Densification Production and Performance Test Results With a Large-Scale Flight-Weight Propellant Tank for the X33 RLV, NASA/TM-2010-216247

[10] Lak T, and Lozano M 1996 Advancement in Cryogenic Propulsion System Performance Through Propellant Densification, AIAA-96-3123

[11] Notardonato W U 2002 NASA Strategic Launch Initiative Propellant Densification Program, Results of the Base Period Work and Future Plans, Proceedings of the 19th International Cryogenic Engineering Conference; pg 533-537, Narosa Publishing, New Delhi India

[12] Notardonato W U, Baik J H, and McIntosh G E 2004 Operational Testing of Densified Hydrogen Using G-M Refrigeration, Advances in Cryogenic Engineering, Vol. 49, American Institute of Physics, New York

[13] Notardonato W U, 2014 Development of a ground operations demonstration unit for liquid hydrogen at Kennedy Space Center, International Cryogenic Engineering Conference, July 7 11, The Netherlands.

[14] Swanger A M, Notardonato W U, and Jumper K M 2015 ASME Section VIII Recertification of a 33,000 Gallon Vacuum-Jacketed LH2 Storage Vessel for Densified Hydrogen Testing at NASA Kennedy Space Center, Proceedings of the ASME Pressure Vessels and Piping Conference, Massachusetts, Boston, pp. V003T03A055, doi:10.1115/PVP2015-45625

[15] Fesmire J E, Tomsik T M, Bonner T, Oliveira J M, Conyers H J, Johnson W L and Notardonato W U 2014 Integrated heat exchanger design for a cryogenic storage tank, Advances in Cryogenic Engineering, AIP Conference. Proceedings, 1573, 1365-1372.

[16] Barron R F 1999 Cryogenic Heat Transfer, Hewitt G F and Tien C L, Philadelphia, PA, TAYLOR \& FRANCIS, p 201 